\title{
O PRINCÍPIO DA INSIGNIFICÂNCIA NA HISTÓRIA DAS IDEIAS PENAIS
}

THE PRINCIPLE OF INSIGNIFICANCE IN THE HISTORY OF CRIMINAL IDEAS

\author{
Adriana de Oliveira Nóbrega ${ }^{1}$ \\ FADIC - PE \\ Altamir Francisco da Silva ${ }^{2}$ \\ FADIC - PE \\ Margarida Cantarelli ${ }^{3}$ \\ FADIC - PE
}

\section{Resumo}

O princípio da insignificância conduz à atipicidade material em caso da irrelevância penal do fato. O trabalho propõe uma análise dele, muitas vezes caracterizado por um acentuado subjetivismo e acientificidade. A pesquisa enfrenta as fragilidades conceituais na aplicação prática do princípio.

Palavras-chave

Princípio da insignificância. Irrelevância penal. Fato.

Abstract

The principle of insignificance leads to material atypicality in case of the criminal irrelevance of the fact. The work proposes an analysis of it, often characterized by a marked subjectivism and acientificity. Research faces conceptual weaknesses in the practical application of the principle.

Keywords

Principle of insignificance. Criminal irrelevance. Fact.

\section{Introdução}

${ }^{1}$ Mestre em Direito pela Faculdade Damas da Instrução Cristã - Recife

2 Professor do Programa de Pós-graduação em Direito da Faculdade Damas da Instrução Cristã. Doutor pelo Pontifício Instituto "Marianum" - Roma.

3 Professora do Programa de Pós-graduação em Direito da Faculdade Damas da Instrução Cristã. Doutora pela UFPE. Desembargadora Federal aposentada do TRF - $5^{\text {a }}$ Região. 
A teoria do delito ordenou e sistematizou todas as regras jurídicas que condicionam a responsabilidade penal e tem como finalidade básica e principal o estudo dos elementos do conceito de delito.

A teoria do delito vincula o juiz penal a uma ordem que tem que seguir na hora de comprovar a punibilidade de um comportamento humano, pois, ao contrário do leigo, inclinado a julgar o comportamento como um todo ou a dirigir a sua atenção rapidamente ao essencial, o penalista está obrigado a contrapor relações e analisá-las separadamente antes de julgar sua totalidade.

A teoria do delito estruturou fundamentalmente o sistema do delito, mediante um método analítico, sobre três categorias básicas, estrutura esta conhecida como o sistema tripartido que se iniciou com von Listz/Beling/Radbruch. Segundo o sistema, o delito é um ato típico, antijurídico e culpável, sendo portanto seus elementos a tipicidade, a antijuridicidade e a culpabilidade. ${ }^{4}$

\section{Aspectos históricos do delito de bagatela: surgimento do princípio da insignificância}

O princípio da legalidade representou passo importante na limitação do poder de punir do Estado frente ao arbítrio absolutista que marcava o tempo que o antecedeu.

Entretanto, com o passar dos anos, a preocupação com eventuais condutas e penas que estivessem fora da lei, e mesmo assim o julgador quisesse o utilizá-las, passou a ser efetivamente com algumas condutas e penas que repousam dentro da lei, mas não se mostraram relevantes. Destarte, mesmo que se amoldassem ao tipo penal, sob o aspecto formal,

4 PAIVA, Rangel Martino de Oliveira. Princípio da insignificância e atipicidade penal. Revista Jurídica da FAMINAS - V. 3, N.1, Jan.-Jul. de 2007. p. 104-105. 
não clamavam, a partir da lesividade da conduta, necessidade de intervenção penal.

O princípio da insignificância surgiu na doutrina como manifestação contrária ao uso excessivo da sanção, quando a conduta do agente não afeta de forma relevante o bem tutelado, não se justificando a atuação do Direito Penal nesses casos. ${ }^{5}$

El principio de insignificancia, entonces nos trae una palabra clave en el análisis, la lesividad. De modo que la acción cometida por el sujeto activo debe tener consecuencias que se traduzcan en una lesión a un bien jurídico, para que se ponga en marcha el aparato judicial. Ahora bien, cuando esa afectación es mínima o insignificante $y$, por consiguiente, no alcanza un dano relevante, no debería ser captado por las agencias penales. ${ }^{6}$

Tanto a doutrina como a jurisprudência são categóricas em reconhecerem a insignificância como princípio jurídico de Direito Penal. Excetuando-se nesse sentido a doutrina europeia, que não considera a insignificância penal como princípio jurídico, e sim o relaciona como princípio da oportunidade no processo penal. ${ }^{7}$

Segundo Hassemer,

Puede ser aconsejable para la descongestión de los tribunales penales y para la agilidad del proceso el

5 SOBRINHO, Fernando Martins Maria; GUARAGNI, Fábio André. O Princípio da Insignificância e sua aplicação jurisprudencial, Revista Jurídica UNICURITIBA, p. 375.

6 MESTRES, Viviana. La legalidad del Principio de la insignificância em el hurto. Revista Cientifica Virtual-RECAMPI, p.175.

7 SILVA, Ivan Luiz da - PRADO, Geraldo (coord). Princípio da Insignificância e os Crimes Ambientais: coleção pensamento crítico. Rio de Janeiro: Lumen Juris, 2008, p.10. 
conceder a las autoridades de instrucción la posibilidad de suprimir el proceso hasta em los hechos punibles (sospechosos) de mediana gravidad. Dado que no se trata de bagatelas (cfr. $1, \mathrm{~b}, 4)$, la suspesión del proceso no puede quedar sin consecuencias; las autoridades de instrucción tienen que ener um poder de sanción limitado (reparación, multas, etcétera). ${ }^{8}$

Não é possível estudar o princípio da insignificância desassociado do princípio da legalidade. O princípio da legalidade em matéria penal sofreu transformações ao longo do tempo que o caracterizaram na mais sólida garantia conferida à liberdade individual dentro de um Estado de regime democrático. Essas transformações foram moldando seu conteúdo numa orientação restritiva ao poder de punir estatal.

Embora a criação do princípio da insignificância seja atribuída a Claus Roxin, tem-se que em 1903, Franz Von Liszt já falava sobre a necessidade de restaurar a máxima mínima non curat pretor como norma, para barrar o crescimento desordenado do Direito Penal.

Encontramos no direito romano o brocado mínima non curat pretor, o qual significava a grosso modo que ao pretor não cabia a análise de casos que envolvessem delitos de bagatela. ${ }^{9}$

Roxin propôs uma solução mediante um recurso à interpretação restritiva dos tipos penais. Formulou, no ano de 1964, o Princípio da Insignificância como princípio de validez geral para a determinação do injusto. ${ }^{10}$

8 HASSEMER, Winfried. La persecución penal legalidad y oportunidad. Jueces para la democracia, v. 4, p. 8-11, 1988.

9 FERNANDES, José Ricardo. Subsídios para a Aplicação do Princípio da Insignificância. Instituto Brasileiro de Ciências Criminais-IBCCRIM. Disponível em: http://www.ibccrim.org.br/site/artigos/imprime.php/jur id=9613. Acesso em 20/04/2015, p. 01. 
A construção intelectual da insignificância como Princípio de Direito Penal foi realizado pelo autor alemão Claus Roxin que defende o caráter principiológico da insignificância penal, além de atribuir-lhe a função de excluir do Direito Penal crimes que, por sua insignificância não chegam a lesionar o bem jurídico tutelado. ${ }^{11}$

Essa ideia de criminalidade bagatelar se fortaleceu com as consequências advindas principalmente da segunda guerra mundial, que provocou um enfraquecimento econômico da Europa. Em decorrência, crimes de pequena monta, como os chamados famélicos, estouravam nos países do velho continente, uma vez que a escassez de empregos e a necessidade de reconstrução de muitos países repercutiam de forma intensa na Europa.

A partir da primeira guerra mundial, com mais vigor no pós segunda grande guerra, quando a população europeia passava por momento de grande dificuldade financeira, em especial a Alemanha que tentava se reerguer no cenário mundial proliferavam crimes de pequena monta, chamados crimes de bagatela, ante a situação de miserabilidade da população. Essa conjectura deu ensejo a judicialização da insignificância, seguindo um caráter predominantemente econômico, patrimonial. ${ }^{12}$

Esta corrente admite a origem fática do princípio na patrimonialidade. A Europa, com problemas crescentes a partir da primeira guerra mundial e em maior medida ao final da segunda guerra, produziu, em virtude de circunstâncias socioeconômicas conhecidas, um notável aumento de delitos de caráter patrimonial e econômico e, facilmente demonstrável pela

10 LOPES, Maurício Antonio Ribeiro. Princípio da insignificância no direito penal: análise à luz das Leis 9.099/95: Juizados Especiais Criminais, Lei 9.503/97: Código de Trânsito Brasileiro, e da jurisprudência atual: série princípios fundamentais do direito penal moderno. 2.ed. São Paulo: RT, 2000, v.2, p.87.

11 SILVA, Ivan Luiz da. PRADO, Geraldo (coord). Princípio da Insignificância e os Crimes Ambientais: coleção pensamento crítico. Rio de Janeiro: Lumen Juris, 2008, p.37.

12 FERNANDES, José Ricardo. Insignificância penal e significância social. Revista Brasileira de História \& Ciências Sociais. Vol. 3. No 5. Julho de 2011, p. 23. 


\section{DELICTAE, Vol. 4, Nº, Jan..-Jun. $2019 \mid 166$}

devastação sofrida pelo continente, quase todos eles marcados pela característica de consistirem em subtrações de pequena relevância, daí a primeira nomenclatura doutrinária de criminalidade de bagatela.

A patrimonialidade é um dado relativo ao início do desenvolvimento do princípio da insignificância. Tem-se pretendido revestir o princípio com um caráter exclusivamente econômico, como que se confundindo os conceitos de propriedade e de patrimônio, tendência contra a qual se insurge volta a doutrina. O Bagateledelikte é um princípio de Direito Penal sujeito a influir, direcionar e determinar o conteúdo de todas as normas penais. É um juízo de valor social que deve ser projetado sobre todas as condutas definidas como crime, informando o Direito Penal com um conteúdo substantivo e apenas autorizando a sua incidência diante de uma avaliação positiva do grau de repercussão jurídico-social de que se deve revestir um fato para ingressar no terreno da incidência das normas penais. $^{13}$

Os "delitos de bagatela" são crimes que inicialmente se revestem de tipicidade, contudo, esta é afastada em razão da lesão ao bem jurídico não provocar uma reprimenda por parte da sociedade, de modo que não se faz preciso a ação das normas de Direito Penal. O valor do princípio da insignificância também pode ser visto na sua atividade limitativa, pois faz com que se restrinja aos atos verdadeiramente ofensivos à coletividade, assegurando desse modo, o conceito de proporcionalidade que as sanções precisam manter com o dano provocado pelo crime. Sendo assim, devemse afastar da seara penal as condutas de importância ínfima, buscando repelir a sobrecarga das lides que acomete o judiciário. Ainda que o princípio da insignificância não esteja expresso no Direito positivo brasileiro, existe sua recepção por parte da legislação, da doutrina e também da jurisprudência, mesmo que aja entendimentos diversos. O

13 PAIVA, Rangel Martino de Oliveira. Princípio da insignificância e atipicidade penal. Revista Jurídica da FAMINAS - V. 3, N.1, Jan.-Jul. de 2007, p. 89 -105. 
princípio da insignificância se ajusta à equidade e correta interpretação do Direito. Por aquela se acolhe um sentimento de justiça, inspirado nos valores vigentes em uma sociedade, liberando-se o agente, cuja ação, por sua inexpressividade, não chega a atentar contra os valores tutelados pelo Direito Penal. ${ }^{14}$

O princípio da insignificância é uma decorrência do próprio modelo do Direito Penal e se funda no princípio da proporcionalidade que deve guiar a intervenção penal no Estado Democrático de Direito. ${ }^{15}$

São vários os fundamentos da não-incidência do Direito Penal quando se trata de infrações bagatelares, como o princípio do dano social, que indica uma pena apenas para uma conduta que ultrapasse a esfera do delito, lesando, a coletividade, o princípio da ofensividade, quando é reprovável e grave lesão ao bem jurídico, o princípio da objetividade jurídica que indica exclusiva proteção aos bens jurídicos que merecem a tutela do Direito Penal e o princípio da adequação social, referente a condutas que são aceitas pela sociedade.

Comungamos da corrente doutrinária que reconhece a insignificância penal como verdadeiro princípio de Direito Penal, derivado da concepção utilitarista do moderno Direito Penal, que impõe para a aplicação de uma pena criminal ao agente a concreta ofensa ao bem jurídico tutelado pela norma penal. ${ }^{16}$

Está fundamentado em princípios constitucionais, cujos valores protegidos são efetivados quando da interpretação restritiva do tipo penal diante do caso concreto.

14 ACKEL FILHO, Diomar. O Princípio da Insignificância no Direito Penal. Revista de Jurisprudência do Tribunal de Alçada de São Paulo. São Paulo: TJSP, v. 94, p.73, abr./jun./1988.

15 PAIVA, Rangel Martino de Oliveira. Princípio da insignificância e atipicidade penal, Op. Cit. p.100.

16 SILVA, Ivan Luiz da. PRADO, Geraldo (coord). Princípio da Insignificância e os Crimes Ambientais: coleção pensamento crítico. Rio de Janeiro: Lumen Juris, 2008, p.10. 
O princípio da insignificância não é um princípio de matriz legal. É uma construção da doutrina e da jurisprudência.

Foi nesse contexto que o princípio da insignificância encontrou campo fértil para prosperar em um flanco em que a aplicação sistemática e irrestrita do princípio da legalidade acabaria produzindo distorções e excessos. Coube a ele, assim, ser um limitador concreto (e não mais abstrato, como a norma penal). Herdeiro natural do princípio da adequação social, o princípio da insignificância assumiu a responsabilidade de encontrar desnecessidade de punição dentre condutas que já se apresentam, inicialmente, delitivas, porque amoldadas ao tipo penal. ${ }^{17}$

O princípio da insignificância está sendo apresentado de forma introdutória para após ser ampliado em sentido e alcance.

\section{A insignificância como cláusula de atipicidade penal}

No momento em que a tipicidade deixou de ser apenas a subsunção do fato à norma e dividiu-se em uma tipicidade formal e outra tipicidade material, quando uma das duas não estiver presente, não se poderá falar em tipicidade do fato. E uma maneira de afastar a tipicidade material, através do princípio da insignificância, é não visualizar lesão ao bem jurídico tutelado. ${ }^{18}$

Nesse contexto, é relevante a análise da tipicidade conglobante e sua aplicação na incidência do princípio da insignificância e na afetação do bem jurídico. A norma não poderá proibir as condutas que não afetem o bem jurídico, isto é, nos casos em que o tipo legal tenha se configurado, mas o bem jurídico não tenha sido afetado, não restará configurada a tipicidade penal. Por os crimes de perigo abstrato visarem à proteção de

17 MENEZES, Bruno Seligman de - PAULI, Cristiane Penning. Tipicidade Penal: Do Princípio da Legalidade ao da Insignificância. Revista Faculdade Direito UFMG, Belo Horizonte, n. 63, jul./dez. 2013, p. 55.

18 Idem, p.45. 
bens jurídicos pertencentes a um número indefinido de pessoas, suscetíveis a uma maior reprovabilidade, são incompatíveis, portanto, com a alegação de inexpressividade da lesão. É neste ponto em que se enquadra parte do objeto do presente estudo: o princípio da insignificância, cuja premissa parte da necessidade de uma afetação relevante ao bem jurídico para que reste configurada a afetação requerida pela tipicidade penal.

O princípio da insignificância como excludente da tipicidade material é a posição que passou a adotar Roxin, e que é majoritariamente aceita, inclusive no Brasil, sendo o posicionamento atual do Supremo Tribunal Federal, ${ }^{19}$ e se a conduta é atípica não há porque ser analisada a culpabilidade do agente.

Diante de uma infração bagatela, o julgador poderia deixar de aplicar o direito penal para não atribuir injustamente responsabilidades penais a casos de inexpressiva relevância social.

Porém, o simples afastamento da lei no caso concreto certamente levaria ao casuísmo e ao subjetivismo, colocando em risco a segurança jurídica quanto às questões criminais.

Paralelamente às questões doutrinárias apresentadas, é inegável que razões práticas de política criminal também tenham sido responsáveis pelo resgate da ideia de insignificância pelos tribunais brasileiros nos últimos anos na seara do direito penal.

A superlotação das penitenciárias, em grande parte, decorrente da privação de liberdade de indivíduos que cometem pequenos delitos, bem como a má qualidade da infraestrutura nelas empregada, além dos questionamentos quanto aos benefícios e prejuízos do encarceramento, tanto na esfera individual quanto na esfera coletiva, tiveram relevância na aplicação do critério da insignificância no Brasil.

19 CINTRA, Adjair de Andrade. Aplicabilidade do Princípio da insignificância aos Crimes que Tutelam Bens Jurídicos Difusos. Universidade de São Paulo. São Paulo. 2011, p.81. 
Dentro do quadro de encarceramento crescente, dos graves problemas estruturais do sistema penitenciário nacional e da necessidade de uma política criminal que evite tanto quanto possível a pena privativa de liberdade, a discussão em torno da insignificância vem ganhando cada vez mais espaço nos tribunais.

Em um país como o Brasil onde existe uma grande discussão acerca de temas como impunidade e corrupção, não há como deixar tais debates ao largo, quando se pretende tratar da insignificância ou não de determinados atos para a sociedade. São claras as motivações que têm conduzido a magistratura brasileira à aplicação do princípio da insignificância no âmbito penal. Há uma crescente demanda processual e com casos em que o prejuízo é tão ínfimo que não justificaria a mobilização de toda a estrutura do Poder Judiciário para solucionar a questão. ${ }^{20}$

\section{Entendimentos contrários ao princípio da insignificância}

Já na antiguidade havia a percepção de que o direito não deve se ocupar com questões irrelevantes, contudo não faz sentido atribuir aos romanos a origem do princípio da insignificância na esfera penal, mas apenas a sua origem remota e genérica. Só podemos falar em direito penal propriamente dito após o movimento iluminista.

Nos séculos XVII e seguintes, houve uma maior preocupação dos estudiosos e da sociedade com a racionalização das punições e do poder punitivo do Estado.

A proposta de se resgatar a máxima romana mínima non curat praetor para corrigir os problemas decorrentes do excessivo formalismo oi bastante sedutora. Contudo, alguns aspectos em torno do princípio da insignificância geraram preocupação na doutrina, a ponto de alguns 
estudiosos rejeitarem a sua utilização. Inúmeras objeções foram opostas ao postulado, embora a controvérsia possa ser dada como superada no país. Os principais pontos opostos referiam-se à sua indeterminação conceitual, à existência de previsão legal de tipos privilegiados, contravenções penais e infrações penais de menor potencial ofensivo, à dificuldade de valoração da ofensa nos delitos não materiais, ã ausência de previsão legal e à sensação de ausncia de direito e de tutela jurídica.

Em relação à indeterminação conceitual, afirmava-se que o princípio da insignificância poderia colocar em isco a segurança jurídica que eve ser proporcionada pelo Direito. Segundo Carlos Vico Manãs, esse fenômeno é o mesmo que ocorreu nos países que adotavam o regime socialista no que tange ao conceito de periculosidade social da ação.

A existência de previsão legal de tipos privilegiados, contravenções penais e infrações de menor potencial ofensivo foi tida como objeção ao princípio da insignificância por alguns autores, não poderia ser acolhido em países que adotam esse tipo e previsão legal, sob pena de se ofender a legalidade em matéria criminal. Contudo, no caso concreto, ao reconhecer a insignificância da ação, sequer submete-a aos tipos penais dessa natureza. A dificuldade de valoração da ofensa no caso dos delitos de natureza não patrimonial também não justifica o afastamento do postulado. Tal entendimento considera tão-somente o desvalor do resultado na configuração do delito insignificante, sem considerar que o desvalor da ação também pode ser levado em conta, como nos crimes de perigo abstrato.

No Brasil, apenas o Código Penal Militar faz referências a situações em que é possível considerar a infração como disciplinar, o que indica a adoção pelo Código, do princípio da insignificância.

$\mathrm{O}$ argumento de que a aplicação concreta do princípio da insignificância gera na sociedade a sensação de ausência de direito e de proteção jurídica também não se sustenta, pois o postulado não se destina a tornar lícitas as condutas insignificantes, mas de afastar da esfera do direito penal o que 
retira dele o seu caráter subsidiário, transferindo para outros ramos do direito a questão da ilicitude. ${ }^{21}$

Ainda que tenha havido alguma oposição à adoção do princípio da insignificância, a inquietação majoritária gira em torno não do seu reconhecimento ou da sua aplicabilidade, mas na melhor forma de sua aplicação. Buscar critérios claros para sua aplicação caso a caso parece ser a melhor saída para a dicotomia entre o necessário formalismo do direito penal e os problemas decorrentes do seu excesso no que tange aos crimes e bagatela.

A forma de aplicação do princípio da insignificância aqui exposta tomará como base as considerações feitas por Yuri Corrêa da Luz, em artigo publicado na Revista GV como veremos adiante.

\section{Aplicação da insignificância como questão de direito material}

A natureza jurídica do princípio da insignificância não é ponto pacífico na doutrina pátria e na jurisprudência. Existem três correntes de pensamento distintas, que defendem o princípio como sendo: excludente de tipicidade, excludente de antijuridicidade e excludente de culpabilidade.

A corrente que caracteriza o princípio da insignificância como excludente de tipicidade é majoritária. Segundo esta corrente doutrinária, as condutas penalmente insignificantes são atípicas, por apresentarem apenas a tipicidade formal e não a material, em face da lesão insignificante ao bem jurídico tutelado.

Compreender a insignificância como questão de direito material seria uma possibilidade de afastar algum dos elementos do conceito analítico do crime. Analisaremos a insignificância como causa excludente de culpabilidade, de antijuridicidade ou de tipicidade.

21 As referidas objeções ao princípio da insignificância foram analisadas com base em MANÃS, Carlo Vico. O princípio da insignificância como excludente da tipicidade no direito penal. São Paulo: Saraiva, 1994, p. 59-70. 


\subsection{Insignificância como causa excludente de culpabilidade do agente}

Os elementos essenciais da culpabilidade são a imputabilidade, a exigibilidade de conduta diversa e a potencial consciência da ilicitude.

Diante de uma infração insignificante, realizar-se á o exame de reprovabilidade pessoal do autor do fato praticado, excluindo-a se diante de uma lesão inexpressiva para os fins penais.

Contudo, a utilização da insignificância como causa excludente de culpabilidade tem a desvantagem de realizar um direito penal do autor e não do fato.

\subsection{Insignificância como causa excludente de antijuridicidade da conduta}

Outra possibilidade seria considerar a insignificância como cláusula justificante da conduta do agente.

O juízo de antijuridicidade verifica se o fato típico está acobertado por alguma circunstância que o justifica, como o estado de necessidade, a legítima defesa, o estrito cumprimento do dever legal ou o exercício regular de um direito.

Examinando essas circunstâncias, realiza-se uma ponderação entre os bens jurídicos envolvidos no caso concreto, confrontando-se a relevância do bem jurídico tutelado pelo tipo penal com a do bem jurídico protegido pela conduta de quem pratica a ação típica.

Entretanto, a questão da antijuridicidade diz respeito ao direito como um todo, de modo que as causas justificantes têm o efeito de torná-las lícitas. A justificação tem o poder de tornar o comportamento legal perante todo o ordenamento, impedindo que se proceda à reparação nos demais âmbitos do direito. 


\subsection{Insignificância como causa excludente da tipicidade da conduta}

Atribui-se à atividade legislativa a imperfeição na definição de tipos que possa conduzir à tipificação formal de comportamentos que deveriam ser excluídos do tipo, tendo em vista que não se amoldariam à exigência do elemento material da tipicidade, que exigem prejuízo ao bem jurídico protegido.

Como não é possível exigir que o legislador previsse todas as hipóteses de ação e omissão possíveis no mundo dos fatos, o julgador pode afastar a tipicidade no caso concreto através do princípio da insignificância.

O critério da insignificância como causa excludente da tipicidade da conduta não leva em consideração questões pessoais afetas ao autor do fato, confirmando um direito penal do fato e não do autor.

É a teoria mais aceita no Brasil, tanto na doutrina como na jurisprudência. A aplicação do princípio da insignificância afasta o aspecto material da tipicidade, embora a conduta insignificante seja contrária ao ordenamento jurídico e ainda que não constitua crime por não se revestir de tipicidade material.

O juízo de tipicidade apenas valora a conduta sob o prisma do Direito Penal, enquanto que o juízo de antijuridicidade avalia a conduta perante todos os ramos do Direito.

Destarte, por não tornar a conduta lícita, mas apenas tolerada pelo direito penal e podendo ainda ser objeto de questionamento em outros ramos do direito, o princípio da insignificância não exclui a antijuridicidade da conduta e como não existe crime, não há razão para a intervenção do direito penal.

Há uma corrente que defende que a análise da culpabilidade do agente na aplicabilidade do princípio da insignificância busca afastar a sua aplicação em relação àqueles que praticam reiteradamente delitos de bagatela. 
Todavia, a análise da culpabilidade do agente só ocorreria se a insignificância não fosse absoluta, mas apenas relativa. ${ }^{22}$

\section{Aplicação da insignificância como questão processual}

A repressão da pequena lesão causada pelo autor do dano deveria ceder diante dos custos sociais de movimentar a máquina estatal desde a abertura do inquérito até a conclusão da fase de execução da pena.

"La mayoría de los países americanos han estabelicido em sus ordenamientos, com menores modificaciones, este supuesto de aplicación que se puede sintetizar de la siguiente manera: es posible aplicar el principio de oportunidad cuando se trate de um hecho insignificante, de mínima culpabilidad del autor o del partícipe, que no afecte gravemente el interés público." 23

Portanto, a insignificância não diria respeito a problemas de ordem material, mas ao princípio da oportunidade, adotado em alguns países como a Alemanha, segundo o qual seria permitido aos órgãos de acusação decidir, em casos específicos e com alguma discricionariedade, propor ou não propor a ação penal eventualmente cabível.

22 LUZ, Yuri Corrêa da. Princípio da Insignificância em Matéria Penal: Entre aceitação ampla e aplicação problemática. In Revista Direito GV, São Paulo 8 (1) I, jan/jun. 2012, p. 83.

23 LUEGAS, Miguel Angel Lamadrid. E1 principio de oportunidad como herramienta de política criminal. Tesi doctoral. Departament de dret Barcelona UPF/2015, p. 258. 


\section{Conclusão}

O princípio da insignificância, apesar de não estar positivado na legislação brasileira, à exceção do Direito Penal militar, é um princípio de interpretação da lei, que vem ganhando espaço na prática penal. Sua aplicação vem se difundindo e não é mais possível negar sua relevância.

Apesar dos benefícios da aplicabilidade do princípio, que privilegia a justiça em detrimento do formalismo exacerbado, é preciso tomar cuidado para que a sua aplicação desordenada não coloque em risco a segurança jurídica e a isonomia esperada do Direito Penal.

A posição em relação ao princípio da insignificância como causa excludente de tipicidade em qualquer hipótese em que se verifica uma infração de bagatela é contestável, pois nem toda infração de bagatela mostra-se isenta de lesividade, gravidade e reprovabilidade do fato face ao bem jurídico protegido.

Distinguir a insignificância absoluta da insignificância relativa, bem como as consequências a que cada uma conduz, pode aumentar o potencial de convencimento dos julgadores e privilegiar a coerência do Direito Penal. De fato, a infração absolutamente insignificante conduz à atipicidade da conduta e por outro lado, a infração relativamente insignificante deveria levar o intérprete a concluir pela desproporcionalidade da sanção.

Neste contexto, é necessário aprofundar o debate sobre essas questões, com o objetivo de superar as fragilidades conceituais apontadas neste trabalho.

\section{Referências}


ACKEL FILHO, Diomar. O Princípio da Insignificância no Direito Penal. Revista de Jurisprudência do Tribunal de Alçada de São Paulo. São Paulo: TJSP, v. 94, abr./jun./1988.

CINTRA, Adjair de Andrade. Aplicabilidade do Princípio da insignificância aos Crimes que Tutelam Bens Jurídicos Difusos. Universidade de São Paulo. São Paulo. 2011.

FERNANDES, José Ricardo. Insignificância penal e significância social. Revista Brasileira de História \& Ciências Sociais. Vol. 3. No 5. Julho de 2011.

Princípio da Insignificância. Instituto Brasileiro de Ciências CriminaisIBCCRIM.

Disponível em: http://www.ibccrim.org.br/site/artigos/imprime.php/jur id=9613. Acesso em 20/04/2015.

HASSEMER, Winfried. La persecución penal legalidad $\mathbf{y}$ oportunidad. Jueces para la democracia, v. 4, 1988.

LOPES, Maurício Antonio Ribeiro. Princípio da insignificância no direito penal: análise à luz das Leis 9.099/95: Juizados Especiais Criminais, Lei 9.503/97: Código de Trânsito Brasileiro, e da jurisprudência atual: série princípios fundamentais do direito penal moderno. 2.ed. São Paulo: RT, 2000, v.2.

LUEGAS, Miguel Angel Lamadrid. E1 principio de oportunidad como herramienta de política criminal. Tesi doctoral Departament de dret Barcelona. UPF/2015.

LUZ, Yuri Corrêa da. Princípio da Insignificância em Matéria Penal: Entre aceitação ampla e aplicação problemática. Revista Direito GV, São Paulo 8 (1) I, jan/jun. 2012.

MENEZES, Bruno Seligman de; PAULI, Cristiane Penning. Tipicidade Penal: Do Princípio da Legalidade ao da Insignificância. Revista Faculdade Direito UFMG, Belo Horizonte, n. 63, jul./dez. 2013.

MESTRES, Viviana. La legalidad del Principio de la insignificância em el hurto. Revista Cientifica Virtual-RECAMPI. 
PAIVA, Rangel Martino de Oliveira. Princípio da insignificância e atipicidade penal. Revista Jurídica da FAMINAS - V. 3, N.1, Jan.-Jul. de 2007.

SILVA, Ivan Luiz da. PRADO, Geraldo (coord). Princípio da Insignificância e os Crimes Ambientais: coleção pensamento crítico. Rio de Janeiro: Lumen Juris, 2008.

SOBRINHO, Fernando Martins Maria - GUARAGNI, Fábio André. O Princípio da Insignificância e sua aplicação jurisprudencial. Revista Jurídica UNICURITIBA, Disponível em: http://revista.unicuritiba.edu.br/index.php/RevJur/article/view/1006 